\title{
Occurrence of and exposure to benzothiazoles and benzotriazoles from textiles and infant clothing
}

\author{
Wenbin Liu ${ }^{\mathrm{a}, \mathrm{b}}$, Jingchuan Xue ${ }^{\mathrm{a}}$, Kurunthachalam Kannan ${ }^{\mathrm{a}, \mathrm{c}, *}$

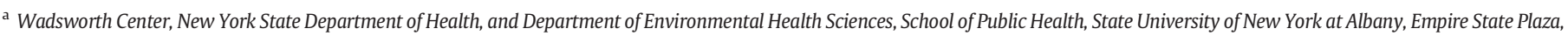 \\ P.O. Box 509, Albany, NY 12201-0509, United States \\ ${ }^{\mathrm{b}}$ Research Center for Eco-Environmental Sciences, Chinese Academy of Sciences, 18 Shuangqing Road, Haidian District, Beijing, 100085, China \\ c Biochemistry Department, Faculty of Science and Experimental Biochemistry Unit, King Fahd Medical Research Center, King Abdulaziz University, Jeddah, Saudi Arabia
}

\section{H I G H L I G H T S}

- Benzothiazoles (BTH) and benzotriazoles (BTR) were measured in infant clothing.

- BTHs were found in $86 \%$ of samples and BTRs were elevated in certain textiles.

- Polyester socks and graphics on clothing had elevated concentrations of BTR.

- Dermal exposure to BTR and BTH from textiles was several tens to hundreds of pg daily.
GRA PH ICA L A B STRACT

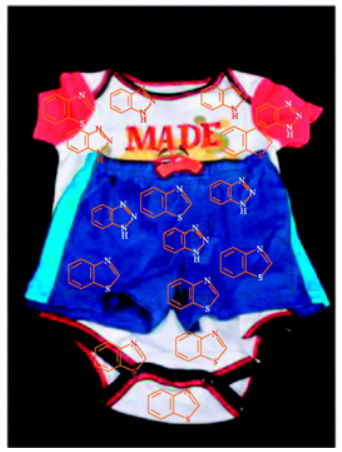

\section{A R T I C L E I N F O}

\section{Article history:}

Received 13 February 2017

Received in revised form 9 March 2017

Accepted 9 March 2017

Available online 29 March 2017

Editor: Adrian Covaci

\section{Keywords:}

Textile

Human exposure

Dermal contact

Children

Cloths

Benzothiazoles

Benzotriazoles

\begin{abstract}
A B S T R A C T
Benzothiazoles (BTHs) and benzotriazoles (BTRs) are used in a wide range of applications, including rubber vulcanization and corrosion inhibition. Limited studies have reported the occurrence of BTHs and BTRs in textiles, including children's clothing. In this study, 79 textile samples (raw as well as tailored) collected in Albany, New York, USA, were analyzed to determine the occurrence of BTH, BTR and their seven common derivatives. BTH, 2-methylthio-benzothiazole (2-Me-S-BTH) and 2-hydroxy-benzothiazole (2-OH-BTH) were found in textiles at a detection rate (DR) of $86 \%, 54 \%$ and $19 \%$, respectively. The DRs of tolyltriazole (TTR), BTR and 5chloro-benzotriazole (5-Cl-BTR) in textiles were below $20 \%$. Although BTH was the most frequently detected compound, BTR levels were elevated in certain textiles and the overall mean concentrations of BTR in textiles were higher than those of BTH. The concentrations of BTH in textiles ranged from 6.1 to $1120 \mathrm{ng} / \mathrm{g}$. The highest concentration of BTR $(14,000 \mathrm{ng} / \mathrm{g})$ was found in a printed graphic of infant's bodysuit. On the basis of the measured concentrations, we calculated dermal exposure doses to BTHs and BTRs by infants. The dermal exposure doses were high from the use of socks (244 to $395 \mathrm{pg} / \mathrm{kg} \cdot \mathrm{bw} / \mathrm{d}$ ), and the exposure doses of BTHs and BTRs from textiles were as high as $3740 \mathrm{pg} / \mathrm{kg} \cdot \mathrm{bw} / \mathrm{d}$. Printed graphics on clothes, as well as socks, accounted for a major proportion of the exposure doses to BTHs and BTRs.
\end{abstract}

(c) 2017 Elsevier B.V. All rights reserved.
* Corresponding author at: Wadsworth Center, Empire State Plaza, P.O. Box 509, Albany, NY 12201-0509, United States.

E-mail address: kurunthachalam.kannan@health.ny.gov (K. Kannan).

\section{Introduction}

The imperative need for textiles in every aspect of our lives is well known. Because textiles are used in various industries such as 
clothing/apparel, construction, home furnishings, automobile and others, the demand for them is constantly increasing, and the textile industry continues to grow significantly worldwide. Textile production comprises conversion of fiber (natural or synthetic) into yarn and then to fabric. Several chemicals are used in textile production to make textiles stronger and more versatile, and for the development of products that provide comfort, wellness, and freshness. A survey conducted by the Transparency Market Research firm in 2015 indicated that textile chemical market is expected to grow at 3.7\% annually from its current U.S. market value of $\$ 21$ billion globally (Transparency Market Research, 2016).

The production of fabric involves several steps that include scouring, bleaching, printing, dyeing, coating, sizing, and plasticizing, among others. A wide variety of chemicals are used in these processes. For example, dyeing involves application of color to textile substrates, mainly with synthetic organic dyes at elevated temperatures and pressures. During this process, along with dyes, many chemical aids such as surfactants, acids, alkali/bases, electrolytes, carriers, leveling agents, promoting agents, chelating agents, emulsifying oils, and softening agents can be applied to obtain a uniform depth of color with fastness. Different types of dyes and chemical additives are used to obtain preferred properties, including anti-fading, water proofing, softening, antistatic protection, soil resistance, stain release and microbial/fungal protection (Chequer et al., 2013). Many of these chemicals are used on textiles to gain these desired benefits, but they also contribute to human and environmental exposures.

Ongoing concerns about the use of chemicals in textiles have prompted increased research into sustainable alternatives. An increasing number of apparel brands and retailers are committing to remove hazardous chemicals from their supply chains (IHS Markit, 2016). In a recent report alerting consumers to dangerous chemicals in products from the European Union, 572 chemical-related notifications involving toys (37\%), jewelry (20\%) and clothing and textiles (13\%) were identified (Chemical Watch, 2016). Other recent studies reported the occurrence of benzothiazoles (BTHs) and benzotriazoles (BTRs) in textiles from Sweden (Avagyan et al., 2015) and toxic metals in textiles from Spain (Rovira et al., 2015; Sungur and Gülmez, 2015; Rovira et al., 2017). A report by Greenpeace showed the presence of a wide range of endocrine disrupting chemicals in textiles, with nonylphenol ethoxylate concentrations as high as 17,000 $\mu \mathrm{g} / \mathrm{g}$ (Greenpeace, 2014).

BTH and BTR are high production volume (HPV) chemicals that have a wide range of applications (Kloepfer et al., 2004). BTH and its derivatives (collectively referred to as BTHs) are commonly used in the vulcanization of rubber (Ni et al., 2008) and as biocides, fungicides, and corrosion inhibitors (Kloepfer et al., 2004). Laboratory animal studies have shown that BTHs are endocrine-disrupting chemicals (Hornung et al., 2015) and genotoxic (Yan et al., 2014). BTHs are also reported to be dermal sensitizers (Wang and Suskind, 1988). BTR and its derivatives (collectively referred to as BTRs) are also HPV chemicals, with an estimated annual production of over 9000 tons in the United States alone (Ferrey et al., 2013). BTRs are the commonly used corrosion inhibitors in deicing fluids for aircrafts, automotive antifreeze formulations, household detergents, and industrial cooling systems (Weiss and Reemtsma, 2005). Commonly known derivatives of BTRs include 4OH-BTR, 5-OH-BTR, XTR and methylated tolyltriazoles (TTR) (Ferrey et al., 2013).

Except for studies from Sweden (Avagyan et al., 2013; Avagyan et al., 2015; Luongo et al., 2016), occurrence of BTHs and BTRs in textiles has not been thoroughly investigated. In our study, several textile products, including infant cloths (blankets, diapers and clothing) were collected from local stores in Albany, New York, USA, to determine the occurrence of BTH, BTR and their derivatives and to evaluate dermal exposure of these chemicals in infants and toddlers. This is the first study to report dermal exposure to BTH and BTR from textiles. The concentrations of BTHs and BTRs were examined on the basis of fabric type (e.g., cotton, polyester, and nylon), countries of origin, and colors.

\section{Materials and methods}

\subsection{Chemicals standards}

Benzothiazole (BTH, CAS\# 95-16-9), 2-hydroxy-benzothiazole (2OH-BTH, CAS\# 934-34-9) and benzotriazole (BTR, CAS\# 95-14-7) were purchased from Alfa Aesar GmbH \& Co KG (Karlsruhe, Germany). 2-Methylthio-benzothiazole (2-Me-S-BTH, CAS\# 615-22-5), 4-hydroxy-benzotriazole hydrate (4-OH-BTR, CAS\# 26725-51-9), 4/5-methyl-1H-benzotriazole (TTR, CAS\# 29878-31-7) and 5-chlorobenzotriazole (5-Cl-BTR, CAS\# 94-97-3) were purchased from SigmaAldrich (St. Louis, MO, USA). 5-Methyl-1H-benzotriazole (5-Me-1HBTR, 98\%), 2-amino-benzothiazole (2- $\left.\mathrm{NH}_{2}-\mathrm{BTH}, \mathrm{CAS} \# 136-95-8\right)$ and 5,6-dimethyl-1H-benzotriazole hydrate (XTR, CAS\# 4184-79-6) were purchased from Acros Organics (Morris Plains, NJ, USA).

The isotope-labeled internal standards (ISs), $\mathrm{d}_{4}-\mathrm{BTH}, \mathrm{d}_{4}-\mathrm{BTR}$ and $\mathrm{d}_{6^{-}}$ Me-BTR, were purchased from Sigma-Aldrich (St. Louis, MO, USA). $\mathrm{d}_{4}$ BTH was used as an IS in the quantification of BTH, 2-OH-BTH, 2-MeS-BTH and 2- $\mathrm{NH}_{2}-\mathrm{BTH} ; \mathrm{d}_{4}$-BTR was used as an IS in the quantification of BTR, 5-Cl-BTR and 4-OH-BTR; $\mathrm{d}_{6}$-MeBTR was used as an IS in the quantification of XTR and TTR. Methanol, dichloromethane, acetone and ethyl acetate were purchased from J. T. Baker (Phillipsburg, NJ, USA). Milli-Q water was purified by an ultrapure water system (Barnstead International, Dubuque, IA, USA).

\subsection{Sample collection and analysis}

Textiles were collected in April 2016 from various retail stores and supermarkets in Albany, New York, USA. A total of 79 samples were analyzed including raw textiles (fabrics) and infant (ages below 1 year) clothing. The textile samples were collected to represent various fabric types (e.g., cotton, polyester, and nylon), colors, and countries of origin. All raw textile ( $n=19$ ) samples originated from China, while the tailored infant clothing $(n=40)$ originated from China $(23 \%)$, India (25\%), Bangladesh (10\%), Sri Lanka (5\%), Vietnam (5\%), Cambodia (20\%), Salvador (5\%) and Ecuador (7\%). Among the clothing, three nylon newborn-size tights ( $94 \%$ with $6 \%$ spandex), thirteen $60 \%$ cotton $/ 40 \%$ polyester blend bodysuits and a number of cotton or cotton/ polyester blend pants, trousers, skirts, and shirts were analyzed. We analyzed two portions within tailored garments of five children's clothing that contained printed graphics/decorations. Nineteen (100\% cotton) raw textiles with different colors were analyzed to examine the influence of the color of dyes on BTH and BTR concentrations. Fourteen types of polyester blend socks for newborns and infants (97-98\% polyester with $1-2 \%$ spandex and up to $1 \%$ latex rubber) were analyzed (all originated from China). In addition, four pre-folded cloth diapers (100\% cotton) and two infant blankets (100\% polyester) were analyzed. A detailed list of samples analyzed in this study is provided in the supporting information (Table S1). The textile samples were stored in polyethylene bags in darkness until analysis.

Approximately $1.4 \mathrm{~g}$ portions of textiles were cut and placed in 15$\mathrm{mL}$ polypropylene (PP) tubes. The samples were spiked with $50 \mathrm{ng}$ of isotope-labeled internal standards $\left(\mathrm{d}_{4}-\mathrm{BTH}, \mathrm{d}_{4}-\mathrm{BTR}\right.$ and $\left.\mathrm{d}_{6}-\mathrm{MeBTR}\right)$. We then added $10 \mathrm{~mL}$ of a mixture of acetone and dichloromethane (v/v: 1/4), ultrasonicated for 20 min, centrifuged, and transferred the supernatant to another PP tube. The samples were extracted twice. Prior to evaporation, a mixture solvent of methanol and acetonitrile ( $5 \mathrm{~mL} ; \mathrm{v} / \mathrm{v}: 1 / 1$ ) was added to the extract. The extract volume was reduced to $0.3 \mathrm{~mL}$ under a gentle stream of nitrogen, and $0.7 \mathrm{~mL}$ methanol was added. We then filtered the extracts through a $0.2 \mu$ nylon filter prior to instrumental analysis.

The samples were analyzed using an Agilent 1100 Series high performance liquid chromatography (HPLC) system (Agilent Technologies Inc., Santa Clara, CA, USA), interfaced with an Applied Biosystems API 2000 electrospray triple quadrupole mass spectrometer (ESI-MS/MS; Applied Biosystems, Foster City, CA, USA). A Zorbax SB-Aq 
(150 mm $\times 2.1 \mathrm{~mm}, 3.5 \mu \mathrm{m})$ column, serially connected to a Javelin guard column (Betasil C18, $20 \mathrm{~mm} \times 2.1 \mathrm{~mm}, 5 \mu \mathrm{m}$ ) was used for chromatographic separation. Further details of the HPLC and MS/MS parameters have been described earlier (Asimakopoulos et al., 2013).

\subsection{Quality assurance and quality control}

Quantification was performed by an isotope-dilution method using the responses of the corresponding ISs. The calibration curve was linear over a concentration range of $0.2 \mathrm{ng} / \mathrm{mL}$ to $200 \mathrm{ng} / \mathrm{mL}$. A midpoint calibration standard and methanol blank were injected after every 10 samples to monitor for drift in instrumental response and carry-over from previous injections. We analyzed procedural blanks with every 10 samples. None of the target chemicals was found in procedural blanks. The method limits of quantitation (MLOQs) for the target chemicals were between $0.7 \mathrm{ng} / \mathrm{g}$ and $4.0 \mathrm{ng} / \mathrm{g}$, estimated as 10 times the signal to noise $(\mathrm{S} / \mathrm{N})$ ratio in the matrix-matched calibration standard. We calculated relative recoveries (RRs) on the basis of pre-extraction and postextraction matrix spiked samples. RRs of BTH, 2-OH-BTH, 2-Me-S-BTH, BTR, TTR and 5-Cl-BTR were from $68 \%$ to $126 \%$ and those for $2-\mathrm{NH}_{2}-$ BTH, XTR and 4-OH-BTR were from $48.9 \%$ to $91.2 \%$. $2-\mathrm{NH}_{2}-\mathrm{BTH}$, XTR and 4-OH-BTR were not detected in any of the samples analyzed. Further details with regard to MLOQ relative recoveries and method performance are presented in the supporting information (Table S2).

\subsection{Dermal exposure assessment}

The measured and detectable concentrations of BTHs and BTRs in textiles were used in the assessment of dermal exposure in infants. The dermal exposure dose was calculated using the following equation (Rovira et al., 2015):

$E X P_{\text {derm }}=C \times D \times S A \times F_{\text {mig }} \times F_{\text {contact }} \times F_{\text {pen }} \times T \times N / B W$

where $\operatorname{EXP}_{\text {derm }}$ is the dermal exposure dose $(\mathrm{pg} / \mathrm{kg} \cdot \mathrm{bw} / \mathrm{d}), \mathrm{C}$ is the concentration of the chemicals in textiles (ng/g), D is the density of the textile $\left(\mathrm{mg} / \mathrm{cm}^{2}\right), \mathrm{SA}$ is the body surface area $\left(2373 \mathrm{~cm}^{2}\right.$ for a toddler) (U.S. Department of Energy, 2014), $\mathrm{F}_{\mathrm{mig}}$ is the migration rate of chemicals from textiles to the skin per day $(0.005 \cdot 1 / \mathrm{d})(\mathrm{BfR}, 2012), \mathrm{F}_{\text {contact }}$ is the fraction of contact area for skin (1, unitless) (BfR, 2012), $\mathrm{F}_{\text {pen }}$ is the penetration rate of chemicals into body (0.01, unitless) (BfR, 2012), $\mathrm{T}$ is the contact duration between textiles and skin (assumed to be $1 \mathrm{~d}$ ) (Rovira et al., 2015), $\mathrm{N}$ is the mean number of events per day (assumed to be 1 1/d) (Rovira et al., 2015), and BW is the average body weight of a toddler (15 kg) (U.S. Department of Energy, 2014).

\section{Results and discussion}

\subsection{Concentrations of BTHs and BTRs in textiles}

We analyzed 79 textiles samples for BTH, BTR and their seven major derivatives. BTH, 2-Me-S-BTH and 2-OH-BTH were found in textiles at a detection rate (DR) of $86 \%, 54 \%$ and $19 \%$, respectively. TTR, BTR and 5-ClBTR were found at a DR of $17 \%, 15 \%$ and $5 \%$, respectively. $2-\mathrm{NH}_{2}-\mathrm{BTH}$, $\mathrm{XTR}$, and 4-OH-BTR were not detected in any of the textile samples analyzed. The concentrations of target chemicals found in textiles are presented in Table 1 (mean, median and range for those samples with measurable values) and Table 2 (mean, median and range for all samples, with samples below the LOQ assigned a value of zero).

BTH was the most frequently detected compound, whereas BTR concentrations were elevated in certain textiles, contributing higher overall mean concentrations. BTH concentrations in those textiles that had measurable values ranged from 6.1 to $1120 \mathrm{ng} / \mathrm{g}$ (overall median: $51.1 \mathrm{ng} / \mathrm{g}$; mean: $117 \mathrm{ng} / \mathrm{g}$ ). The mean concentrations of BTH derivatives, 2-Me-S-BTH and 2-OH-BTH, were 3 to 10 times lower than those of BTH (Table 1). Nevertheless, 2-Me-S-BTH and 2-OH-BTH

\section{Table 1}

Concentrations (ng/g) of benzothiazoles (BTHs) and benzotriazoles (BTRs) in textile samples collected from Albany, New York, USA, sorted by the uses ${ }^{\mathrm{a}}$.

\begin{tabular}{|c|c|c|c|c|}
\hline & $d^{b}$ & Mean \pm SD & Median & Range \\
\hline \multicolumn{5}{|c|}{ Raw textiles $(n=19)$} \\
\hline BTH & 13 & $22.5 \pm 17.1$ & 16.5 & $6.1-68.8$ \\
\hline 2-Me-S-BTH & 1 & n.a. & n.a. & 2.1 \\
\hline 5-Cl-BTR & 2 & n.a. & n.a. & $46.4 ; 113$ \\
\hline \multicolumn{5}{|c|}{ Diaper $(n=4)$} \\
\hline BTH & 4 & $16.6 \pm 2.03$ & 16.4 & $14.8-18.8$ \\
\hline 2-Me-S-BTH & 1 & n.a. & n.a. & 2.8 \\
\hline \multicolumn{5}{|c|}{ Blanket $(n=2)$} \\
\hline BTH & 2 & n.a. & n.a. & $12.7 ; 19.5$ \\
\hline TTR & 1 & n.a. & n.a. & 12.8 \\
\hline BTR & 2 & n.a. & n.a. & $4.2 ; 21.6$ \\
\hline \multicolumn{5}{|c|}{ Cloths $(n=37)$} \\
\hline BTH & 35 & $74.3 \pm 49.3$ & 59.7 & $19.1-232$ \\
\hline 2-OH-BTH & 10 & $42.1 \pm 20.6$ & 32.9 & $20.5-80.1$ \\
\hline 2-Me-S-BTH & 31 & $13.2 \pm 12.5$ & 8.5 & $2.1-47.3$ \\
\hline BTR & 6 & $3010 \pm 5450$ & 777 & $26.8-14,000$ \\
\hline \multicolumn{5}{|c|}{ Socks $(n=17)$} \\
\hline BTH & 14 & $356 \pm 375$ & 154 & $89.9-1120$ \\
\hline 2-OH-BTH & 5 & $63.8 \pm 29.5$ & 57.4 & $23.9-95.7$ \\
\hline 2-Me-S-BTH & 10 & $8.55 \pm 6.07$ & 8 & $3.1-24.5$ \\
\hline BTR & 4 & $235 \pm 297$ & 134 & $16.2-656$ \\
\hline TTR & 12 & $88.7 \pm 109$ & 25.4 & $6.7-270$ \\
\hline 5-Cl-BTR & 2 & n.a. & n.a. & $4.2 ; 7.4$ \\
\hline \multicolumn{5}{|c|}{ Total $(n=79)$} \\
\hline BTH & 68 & $117 \pm 210$ & 51.1 & $6.1-1120$ \\
\hline 2-OH-BTH & 15 & $49.3 \pm 25.1$ & 33.9 & $20.5-95.7$ \\
\hline 2-Me-S-BTH & 43 & $11.6 \pm 11.3$ & 7.9 & $2.1-47.3$ \\
\hline BTR & 12 & $1590 \pm 3970$ & 142 & $4.2-14,000$ \\
\hline TTR & 13 & $82.9 \pm 107$ & 24.7 & $6.7-270$ \\
\hline 5-Cl-BTR & 4 & $42.8 \pm 50.6$ & 26.9 & $4.2-113$ \\
\hline
\end{tabular}

a Non-detects were not included in the calculation.

b $\mathrm{d}=$ number of samples with detectable concentrations.

were present in some textile samples at concentrations higher than those of BTH. The concentrations of 2-Me-S-BTH in those textiles that had measurable concentrations ranged from 2.1 to $47.3 \mathrm{ng} / \mathrm{g}$ (overall median: $7.9 \mathrm{ng} / \mathrm{g}$; mean: $11.6 \mathrm{ng} / \mathrm{g}$ ). Although the DR of 2-OH-BTH (19\%) was lower than that of 2-Me-S-BTH (54\%), the concentrations were generally higher than those of 2-Me-S-BTH in textiles, with the concentrations ranging from $20.5 \mathrm{ng} / \mathrm{g}$ to $95.7 \mathrm{ng} / \mathrm{g}$ (Table 1, overall median: $33.9 \mathrm{ng} / \mathrm{g}$; mean: $49.3 \mathrm{ng} / \mathrm{g}$ ). Avagyan et al. (2013) determined the concentrations of BTHs in an infant cloth made of $100 \%$ polyester and found $8640 \pm 430 \mathrm{ng} / \mathrm{g}$ for BTH and $738 \pm 100 \mathrm{ng} / \mathrm{g}$ for 2-Me-S-BTH, which were much higher than the concentrations found in our study.

BTR concentrations ranged widely from 4.2 to $14,000 \mathrm{ng} / \mathrm{g}$; certain sections of infant garment had higher levels of this compound. The highest concentration of BTR $(14,000 \mathrm{ng} / \mathrm{g})$ was found in a printed, graphic portion of a boys' (6-9 month old) bodysuit. The rest of the fabric contained a BTR concentration of $948 \mathrm{ng} / \mathrm{g}$. The chest portion of the bodysuit had a density of $33.7 \mathrm{mg} / \mathrm{cm}^{2}$ in comparison to $18.1 \mathrm{mg} / \mathrm{cm}^{2}$ in other portions of the garment. This bodysuit was labeled as containing $60 \%$ cotton and $40 \%$ polyester fabric 'exclusive of decoration'. Elevated concentrations of BTR in the graphic portion (i.e., 'decoration') of that bodysuit suggested the presence of other material contributing to high concentrations of BTR. The graphic portion was rubbery in texture. The second highest concentration of BTR ( $2250 \mathrm{ng} / \mathrm{g}$ ) was found in a red and yellow graphic print on the chest of boys' (3-6 month old) bodysuit. The remainder of the bodysuit had a BTR concentration of $38 \mathrm{ng} / \mathrm{g}$. Although cloths with dyes/decorative/graphic prints had higher levels of BTRs, this compound was rarely detected (15\%) in colored raw textiles analyzed in this study. It is possible that some of the graphic/printed portions of garments used materials/fabric (e.g., rubber) that contained elevated concentrations of BTR. High concentrations of TTR (mean: $234 \mathrm{ng} / \mathrm{g}$ ) were found in four newborn high-cut socks 
Table 2

Concentrations $(\mathrm{ng} / \mathrm{g}$ ) of benzothiazoles and benzotriazoles in textile samples sorted by the uses ${ }^{\mathrm{a}}$.

\begin{tabular}{|c|c|c|c|c|}
\hline & $d^{b}$ & Mean \pm SD & Median & Range \\
\hline \multicolumn{5}{|c|}{ Raw textiles $(n=19)$} \\
\hline BTH & 13 & $15.4 \pm 17.6$ & 11.7 & $<$ MLOQ-68.8 \\
\hline 2-Me-S-BTH & 1 & n.a. & n.a. & 2.1 \\
\hline 5-Cl-BTR & 2 & n.a. & n.a. & $46.4 ; 113$ \\
\hline \multicolumn{5}{|c|}{ Diaper $(n=4)$} \\
\hline BTH & 4 & $16.6 \pm 2.03$ & 16.4 & $14.8-18.8$ \\
\hline 2-Me-S-BTH & 1 & n.a. & n.a. & 2.8 \\
\hline \multicolumn{5}{|c|}{ Blanket $(n=2)$} \\
\hline BTH & 2 & n.a. & n.a. & $12.7 ; 19.5$ \\
\hline TTR & 1 & n.a. & n.a. & 12.8 \\
\hline BTR & 2 & n.a. & n.a. & $4.2 ; 21.6$ \\
\hline \multicolumn{5}{|c|}{ Cloths $(n=37)$} \\
\hline BTH & 35 & $70.3 \pm 50.8$ & 55.1 & $<$ MLOQ-232.6 \\
\hline 2-OH-BTH & 10 & $11.4 \pm 21.5$ & $<$ MLOQ & $<$ MLOQ-80.1 \\
\hline 2-Me-S-BTH & 31 & $11.1 \pm 12.4$ & 7.4 & $<$ MLOQ-47.3 \\
\hline BTR & 6 & $488 \pm 2322$ & $<$ MLOQ & $<$ MLOQ-14000 \\
\hline \multicolumn{5}{|c|}{ Socks $(n=17)$} \\
\hline BTH & 14 & $293 \pm 365$ & 144 & $<$ MLOQ-1120 \\
\hline 2-OH-BTH & 5 & $18.8 \pm 33.4$ & $<$ MLOQ & $<$ MLOQ-95.7 \\
\hline 2-Me-S-BTH & 10 & $5.03 \pm 6.29$ & 3.4 & $<$ MLOQ-24.5 \\
\hline BTR & 4 & $55.3 \pm 165$ & $<$ MLOQ & $<$ MLOQ-656 \\
\hline TTR & 12 & $62.6 \pm 99.7$ & 8 & $<$ MLOQ-270 \\
\hline 5-Cl-BTR & 2 & n.a. & n.a. & $4.2 ; 7.4$ \\
\hline \multicolumn{5}{|c|}{ Total $(n=79)$} \\
\hline BTH & 68 & $101 \pm 199$ & 44 & $<$ MLOQ-1120 \\
\hline 2-OH-BTH & 15 & $9.36 \pm 22.2$ & $<$ MLOQ & $<$ MLOQ-95.7 \\
\hline 2-Me-S-BTH & 43 & $6.32 \pm 10.1$ & 2.8 & $<$ MLOQ-47.3 \\
\hline BTR & 12 & $241 \pm 1596$ & $<$ MLOQ & $<$ MLOQ-14000 \\
\hline TTR & 13 & $13.6 \pm 52$ & $<$ MLOQ & $<$ MLOQ-270 \\
\hline 5-Cl-BTR & 4 & $2.17 \pm 13.7$ & $<$ MLOQ & $<$ MLOQ-113 \\
\hline
\end{tabular}

a Non-detects were given a value of " 0 " for the calculation.

b $\mathrm{d}=$ number of samples with detectable concentrations.

samples, and high concentrations of 5-Cl-BTR (mean: $80 \mathrm{ng} / \mathrm{g}$ ) were found in two blue denim samples.

BTR was reported to occur in $8 \%$ of the textile samples from Sweden, and the highest concentration found in that study was $3040 \mathrm{ng} / \mathrm{g}$ (Avagyan et al., 2015). The frequency of detection of BTR is our study is approximately twice that reported in Sweden. However, BTH was the most frequently detected compound in our study. We also presented the mean and median concentrations of BTHs and BTRs in various textiles analyzed in this study by substituting a value of zero for those samples with values below the LOQ (Table 2). BTH had the highest concentration followed by 2-Me-S-BTH, two most frequently detected compounds in textiles (Table 2). The exact source of BTHs and BTRs in textiles is not known, but these chemicals are used in certain fabrics (as described below) to improve the performance and durability of the products.

\subsection{Concentrations of BTHs and BTRs in cotton textiles grouped by colors}

We also evaluated synthetic dyes as potential sources for BTHs and/ or BTRs in our textile samples. The concentrations of BTH in textile samples of various colors are presented in Fig. 1. Only BTHs were found in raw cotton textiles $(n=19)$, and their concentrations ranged from 6.1 to $69 \mathrm{ng} / \mathrm{g}$. BTH concentrations in 100\% raw cotton textiles did not appear to vary depending on the color. The highest concentration was found in a black-colored cloth, but another brand of black cloth did not contain measurable levels of BTH. Similarly, although one white garment had a BTH concentration of $23 \mathrm{ng} / \mathrm{g}$, two other brands of white $100 \%$ cotton textiles did not contain measurable concentrations of this compound. Thus, although there were minor differences in the concentrations of BTHs in textiles depending on the colors, these differences appeared to be unrelated to the color of dyes.

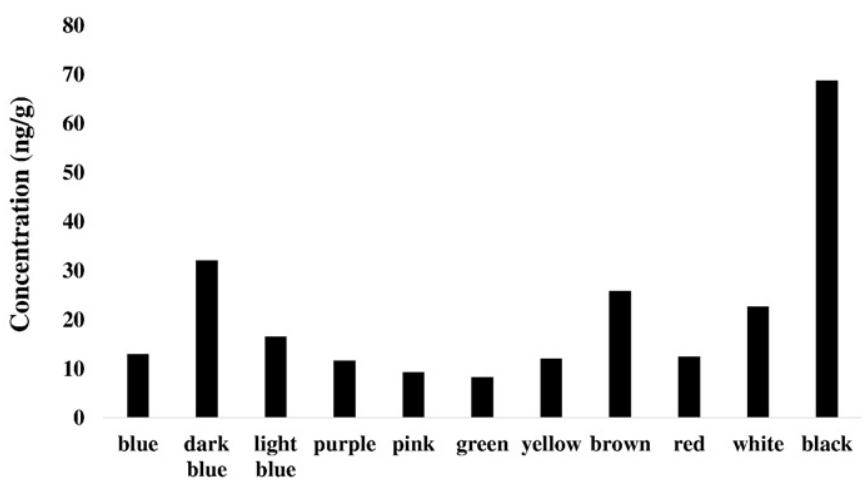

Fig. 1. Concentrations of benzothiazole (BTH) in $100 \%$ raw cotton textiles with various colors (sample number for each color varies from 1 to 3 ).

\subsection{BTH and BTR concentrations in relation to fabric type}

The concentrations of BTHs and BTRs in textiles and cloths as related to the fabric type are presented in Fig. 2. The concentrations of BTHs and BTRs in raw cotton textiles, $100 \%$ cotton cloth diapers, and $100 \%$ polyester blankets were low. Cloth diapers and blankets contained total BTR and BTH concentrations at 17.2 and $35.5 \mathrm{ng} / \mathrm{g}$, respectively. The concentrations of BTHs in polyester fabrics were higher than those in $100 \%$ cotton and nylon textiles, suggesting that manufacture of polyester may involve the use of BTHs. Four type of newborn socks with $98 \%$ polyester contained the highest mean BTH concentration of $905 \mathrm{ng} / \mathrm{g}$; these samples also contained a high mean concentration of TTR $(234 \mathrm{ng} / \mathrm{g})$ and 2OH-BTH (73.7 ng/g). Presence of high levels of BTHs/BTRs in socks for newborns signifies dermal exposure through the feet. In all of the socks samples analyzed, polyester was blended with other fabric such as $1-2 \%$ spandex and $1 \%$ latex rubber. Spandex is a synthetic fiber used in clothing industry for its elasticity and strength. This fiber is mainly used in active wear, hosiery, elastic waistbands, socks, gloves, underwear and many other skin-tight clothing. An estimated $80 \%$ of clothing sold in the United States contained spandex in 2010. During the production of spandex, antioxidants and UV light stabilizers are added to prevent photo-degradation of the fibers. BTHs and BTRs may be added to enhance strength and durability of the product (Jerde, 1992). Presence of the spandex fiber may be a source of BTH and BTR in many skin-tight clothing. However, three infant tights that originated from Ecuador ( $94 \%$ nylon and 6\% spandex) did not contain BTH and BTR, which suggests that the country of manufacture can introduce variability in contamination levels in textiles. It also cannot be ignored that the sock samples contained $1 \%$ natural latex rubber, which can be a source for BTH. Further studies are needed to evaluate the origin of contaminants in textile fibers. It is worth to note that each newborn sock weighed between 4.7 and $5.7 \mathrm{~g}$ (mean: $5.2 \mathrm{~g}$ ). Considering the respective median and maximum BTR concentrations of 142 and $14,000 \mathrm{ng} / \mathrm{g}$, the total amount of BTR in each sock was estimated to be $740 \mathrm{ng}$ and $73,000 \mathrm{ng}$, respectively.

\subsection{Dermal exposure to BTHs and BTRs via textiles}

The estimated dermal exposure doses of BTHs and BTRs by infants through direct skin contact with textiles are shown in Fig. 3. For this calculation, we used a worst-case exposure scenario for children according to the U.S. EPA's risk assessment information system. The calculated dermal exposure doses for infants from BTRs and BTHs ranged from 0 to $3740 \mathrm{pg} / \mathrm{kg} \cdot \mathrm{bw} / \mathrm{d}$, with an mean value of $92 \mathrm{pg} / \mathrm{kg} \cdot \mathrm{bw} / \mathrm{d}$. Infant cloths with printed graphics and decorative portions, as well as socks with certain types of synthetic fibers, were the major contributors to dermal exposures. Socks made up of $98 \%$ polyester contributed to BTH exposures in the range of 244 to $395 \mathrm{pg} / \mathrm{kg} \cdot \mathrm{bw} / \mathrm{d}$, with combined BTH 


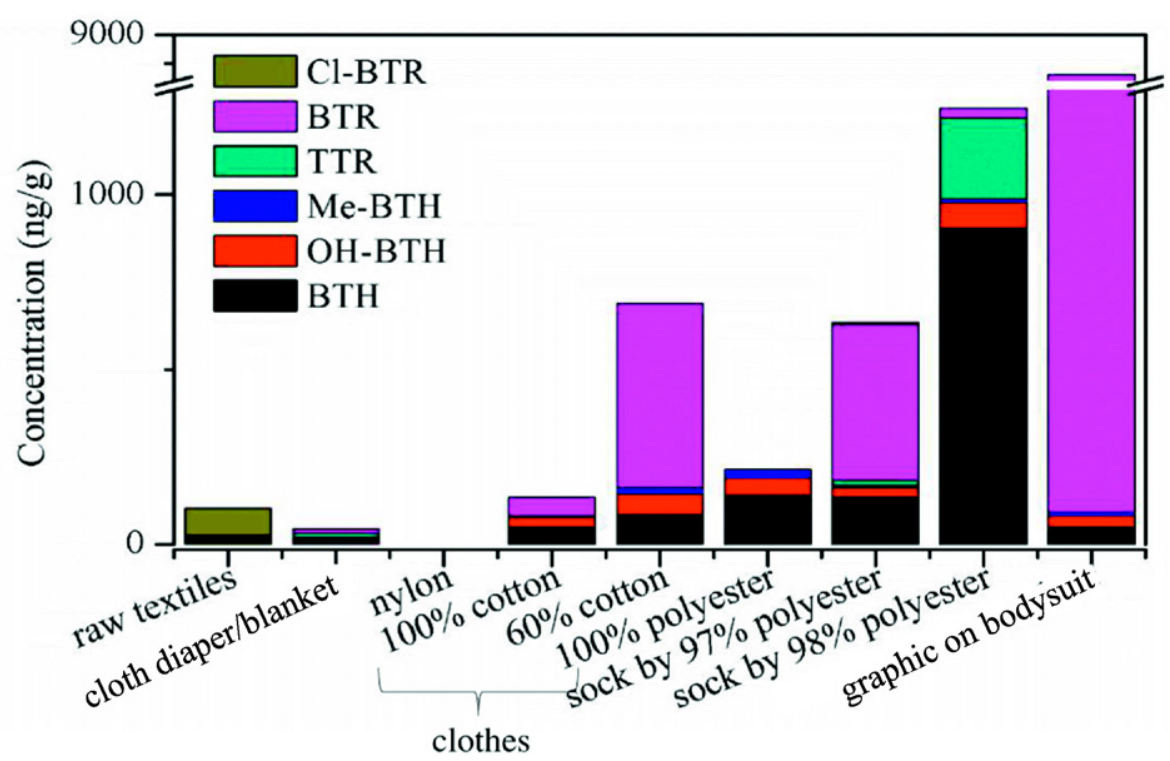

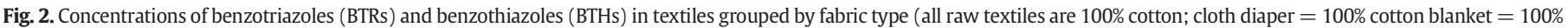
polyester; nylon refers to tights with $94 \%$ nylon and $6 \%$ spandex).

plus BTR exposures in the range of 369 to $533 \mathrm{pg} / \mathrm{kg} \cdot \mathrm{bw} / \mathrm{d}$. The highest exposure to BTRs ( $3740 \mathrm{pg} / \mathrm{kg}$. bw/d) was from a themed graphic imprint on the chest portion of a bodysuit.

Select BTHs and BTRs have been measured in textiles by Avagyan et al. (2013) and Luongo et al. (2016) earlier. However, this study reports for the first time that BTHs and BTRs are found in many textiles, including infants' cloths, and that clothing can be a source of dermal exposure to these contaminants. However, it should be noted that our study has some limitations. First, textiles available in the market vary widely in their composition, with different fabric types, colors, and mixtures of various fibers found within a single piece of garment. Even a single piece of garment has several parts that can be different in composition (in terms of dyes and fabrics used). Therefore, generalizing from average concentrations of chemicals present in a single piece of garment can under- or overestimate the actual values. Second, the concentrations measured in textiles represent only the solvent-extractable fraction of the chemicals from textiles, which may not represent the actual amount present in textiles. The actual concentration may be higher than what was extracted by organic solvents, while the bioavailable fraction may be lower (Rezic and Steffan, 2007; Rovira et al., 2017). Third, the exposure assessment in this study was based on certain assumptions regarding dermal penetration rate and body surface area, and selected worst-case scenarios for exposure were employed. However, such assumptions are inherent in exposure and risk assessment calculations. Chemical specific migration rate and dermal permeation rate for these chemicals should be elucidated in future studies. Furthermore, a reference value is not available to compare against the exposure dose calculated in this study. Fourth, we assumed that the textiles were worn new (prior to washing) and therefore, the effect of washing on the removal of chemicals from textiles needs further investigation. Some BTHs and BTRs in textiles do not get removed completely even after washing several times (Luongo et al., 2016). Furthermore, only textiles

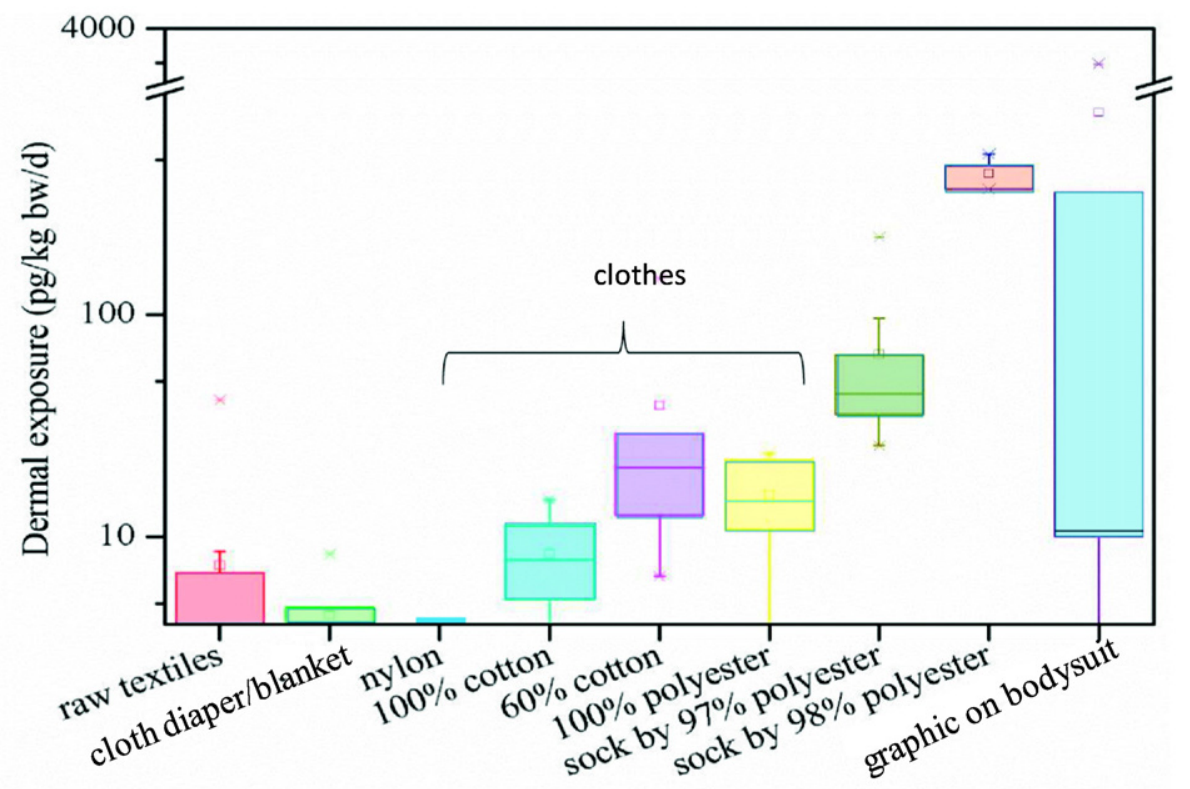

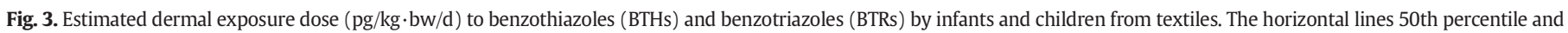
the boxes represent 25 th and 75 th percentiles. 
with measurable concentrations of BTH and BTR were used in exposure assessment, and this could have led to an overestimation of the actual exposure doses. Furthermore, infants and children often chew and suck cloths, and therefore exposure of this age group to chemicals present in cloths is an even greater concern. This study also suggests that clothes can be a source of BTHs and BTRs released into the wastewater stream. In general, this study presents important information that textiles are a source of exposure to certain environmental chemicals to infants as well as adults. These findings indicate the need for further studies on the sources and exposure levels of chemicals present in textiles.

\section{Acknowledgments}

We thank Mr. Karl Brosch for help with the collection of samples.

\section{Appendix A. Supplementary data}

Supplementary data to this article can be found online at http://dx. doi.org/10.1016/j.scitotenv.2017.03.090.

\section{References}

Asimakopoulos, A.G., Bletsou, A.A., Wu, Q., Thomaidis, N.S., Kannan, K., 2013. Determination of benzotriazoles and benzothiazoles in human urine by liquid chromatographytandem mass spectrometry. Anal. Chem. 85, 441-448.

Avagyan, R., Sadiktsis, I., Thorsen, G., Ostman, C., Westerholm, R., 2013. Determination of benzothiazole and benzotriazole derivates in tire and clothing textile samples by high performance liquid chromatography-electrospray ionization tandem mass spectrometry. J. Chromatogr. A 1307, 119-125.

Avagyan, R., Luongo, G., Thorsén, G., Östman, C., 2015. Benzothiazole, benzotriazole, and their derivates in clothing textiles-a potential source of environmental pollutants and human exposure. Environ. Sci. Pollut. Res. 22, 5842-5849.

BfR, 2012. Introduction to the Problems Surrounding Garment Textiles. http://159.226. 240.76/www.bfr.bund.de/cm/349/introduction-to-the-problems-surroundinggarment-textiles.pdf accessed 2012.06.06.

Chemical Watch, 2016. Chemicals Become Most Reported Product Risk. https:// chemicalwatch.com/46942/chemicals-become-most-reported-product-risk accessed 2016.04.26.

Chequer, F.M.D., de Oliveira, G.A.R., Ferraz, E.R.A., Cardoso, J.C., Zanoni, M.V.B., de Oliveira, D.P., 2013. Textile dyes: dyeing process and environmental impact. In: Günay, Melih (Ed.), Eco-Friendly Textile Dyeing and Finishing.
Ferrey, M., Streets, S., Lueck, A., 2013. Pharmaceuticals and Personal Care Products in Minnesota's Rivers and Streams: 2010. Minnesota Pollution Control Agency.

Greenpeace, 2014. Dirty laundry: Unravelling the Corporate Connections to Toxic Water Pollution in China. Published by Greenpeace International, Amsterdam, The Netherlands, p. 116.

Hornung, M.W., Kosian, P.A., Haselman, J.T., Korte, J.J., Challis, K., Macherla, C., Nevalainen, E., Degitz, S.J., 2015. In vitro, ex vivo, and in vivo determination of thyroid hormone modulating activity of benzothiazoles. Toxicol. Sci. 146, 254-264.

IHS Markit, 2016. Specialty Chemicals Update Program: Textile Chemicals. https://www. ihs.com/products/chemical-textile-scup.html accessed 2016.03.

Jerde, J., 1992. Encyclopedia of Textiles. Facts on File.

Kloepfer, A., Jekel, M., Reemtsma, T., 2004. Determination of benzothiazoles from complex aqueous samples by liquid chromatography-mass spectrometry following solidphase extraction. J. Chromatogr. A 1058, 81-88.

Luongo, G., Avagyan, R., Hongyu, R., Ostman, C., 2016. The washout effect during laundry on benzothiazole, benzotriazole, quinoline, and their derivatives in clothing textiles. Environ. Sci. Pollut. Res. Int. 23, 2537-2548.

Ni, H.G., Lu, F.H., Luo, X.L., Tian, H.Y., Zeng, E.Y., 2008. Occurrence, phase distribution, and mass loadings of benzothiazoles in riverine runoff of the Pearl River Delta, China. Environ. Sci. Technol. 42, 1892-1897.

Rezic, I., Steffan, I., 2007. ICP-OES determination of metals present in textile materials. Microchem. J. 85, 46-51.

Rovira, J., Nadal, M., Schuhmacher, M., Domingo, J.L., 2015. Human exposure to trace elements through the skin by direct contact with clothing: risk assessment. Environ. Res $140,308-316$

Rovira, J., Nadal, M., Schuhmacher, M., Domingo, J.L., 2017. Trace elements in skin-contact clothes and migration to artificial sweat: risk assessment of human dermal exposure. Text. Res. J. 87, 726-738.

Sungur, S., Gülmez, F., 2015. Determination of metal contents of various fibers used in textile industry by MP-AES. J. Spectrosc. 2015, 1-5.

U.S. Department of Energy, 2014. RAIS, The Risk Assessment Information System. http:// rais.ornl.gov/ accessed 2014.12.

Transparency Market Research, 2016. Textile Chemicals Market - Global Industry Analysis, Size, Share, Growth, Trends and Forecast 2016-2024. http://www. transparencymarketresearch.com/textile-chemicals-market.html accessed 2016.05.05.

Wang, X., Suskind, R.R., 1988. Comparative studies of the sensitization potential of morpholine, 2-mercaptobenzothiazole and 2 of their derivatives in Guinea pigs. Contact Dermatitis 19, 11-15.

Weiss, S., Reemtsma, T., 2005. Determination of benzotriazole corrosion inhibitors from aqueous environmental samples by liquid chromatography-electrospray ionizationtandem mass spectrometry. Anal. Chem. 77, 7415-7420.

Yan, Y., Jiang, W.W., Li, N., Ma, M., Rao, K.F., Wang, Z.J., 2014. Application of the SOS/umu test and high-content in vitro micronucleus test to determine genotoxicity and cytotoxicity of nine benzothiazoles. J. Appl. Toxicol. 34, 1400-1408. 